\title{
Continuous Quality Improvement in Higher Education
}

\author{
Robert V. Hogg1 and Mary C. Hogg 2
}

${ }^{1}$ Department of Statistics and Actuarial Science, The University of Iowa, Iowa City, IA 52242, USA

${ }^{2}$ Speech Communication Department, Eastern Illinois University, Charleston, IL 61920, USA

"TQM comprises more than statistics; but, without statistics, it is often 'smoke and mirrors'." (Harry V. Roberts, University of Chicago)

\section{Summary}

Higher education faces a new era as a result of changes in the way people view colleges and universities. Expectations for better performance in terms of teaching and producing competent college graduates are increasing. One model for higher education is the success of many companies that have bettered their overall performance and products using "total quality management" (TQM). TQM is primarily concerned with increasing customer satisfaction through an integrated framework that examines the relationships between various systemwide elements and makes data-driven decisions to reduce errors and waste in processes. To do this, managers must create an environment in which employees take joy and pride in their work and are empowered to make changes.

This paper examines the need for continuous quality improvement in higher education; the role of academic statisticians in changes in higher education; some of the strategies and techniques colleges and universities are employing related to TQM at college and department levels; what individual instructors can do in terms of making improvements in higher education; and the role and importance of a personal quality vision in such an overall effort for organizational change. In addition, it is the authors' intent that the paper be a source for ideas about improving teaching and ways to think about issues related to TQM on campus.

Key words: Continuous Quality Improvement; Total Quality Management; Personal quality; Organizational change.

\section{Introduction}

The need for change in higher education is becoming urgent. Increasingly, students are frustrated with their experiences as education consumers. Seymour (1992) demonstrates that students want "quality" to extend beyond the size of their school's endowment or the research credentials of senior faculty. He cites the front-page Chronicle of Higher Education article, "Undergraduates at Large Universities Found to be Increasingly Dissatisfied," (Wilson, 1991) as evidence of the need to develop a service orientation on college campuses. A disenchanted University of Texas at Austin sophomore is quoted as saying, "Here, it's not what the system can do for you, but what you can do to make the system work for you. You have to fight it." (p.7).

National Science Foundation assistant director John S. White's questions to a room of educators make explicit that businesses could not tolerate higher education's high rates of "rejected parts" (attrition), late deliveries (delayed graduations), price raises (tuition increases); and "rework" (students having to take courses over again): 
"How long would a firm be in business if it rejected parts and subassemblies at an overall rate of 35 percent and rejected a critical component at a rate of 65 percent? How long would a firm be in business if it consistently failed to meet its advertised delivery dates by 25 percent? . . . How long would a firm be in business if it paid little attention to its cost of production, but instead raised prices at a rate considerably above the cost of living while competitors entered the market with lower prices?" (Seymore, 1992, p.21).

Given that undergraduate attrition rates in the U.S. are approximately one-third, that failure rates for courses are often one-tenth, that absentee rates for relatively large lecture courses are sometimes over one-half, and that most universities have low alumni retention rates (about one-quarter), colleges and universities clearly need to examine how they can better meet the needs of their students and alumni.

In the United States, students, parents, legislators, businesses, and the general public are becoming increasingly dissatisfied with the higher education that is currently being provided. Some complaints are: students are unable to register for courses because sections are full; many courses are taught not by faculty but by graduate teaching assistants; faculty do not appear committed to teaching. On a related note, there is a total lack of training for professors in pedagogical and learning processes. University students in other countries have similar complaints about large courses, lack of access to faculty, and haphazard teaching. These are systematic problems that are difficult to change without budgetary means. However, an overall concern for continuous Quality Improvement (CQI) on college campuses could significantly improve higher education and the satisfaction of its students and alumni.

While the educational "product" is not the same as that of industry, higher education can improve the way it offers and delivers courses, provides student services, and manages and conducts research. TQM can help universities find solutions as it stresses continuous improvement of processes and products by listening to the stakeholders (customers, employees, investors, suppliers, society) of any organization. Since, however, the words, management and to some extent total, sound too businesslike to the faculty, we suggest the expression Continuous Quality Improvement (CQI). CQI is often used in health care as physicians find this expression more acceptable. As a matter of fact, education can learn a great deal from improvements in health care as there is a similar service orientation (Berwick et al, 1990). So, hereinafter, TQM and CQI are used interchangeably, although we prefer the latter expression.

\section{The Role of Business}

In general, Business, Industry, and Government (BIG) are not happy with U.S. college and university graduates. In statistics, for example, they feel that students should work on more projects from inception to completion. Improvement of the communication skills of students would also be welcomed by BIG. Some businesses are trying to help higher education do something about its problems. Yet no major university has totally adopted the philosophy of TQM, and only a few have made significant improvements in certain aspects (mainly non-academic) of their operations.

In a 1991 issue of the Harvard Business Review, the CEO's of six major companies (American Express, Ford, IBM, Motorola, Procter \& Gamble, and Xerox) wrote "An Open Letter: TQM on the Campus", in which they proposed partnerships between business an academia. These partnerships would foster a shared responsibility to learn, to teach, and to practice TQM. They proposed that presidents, deans, and faculty leaders attend week-long sessions at each of the six companies to study ways to: 1) identify the core knowledge specific to TQM; 2) develop a research agenda in TQM; and 3) develop faculty understanding of and commitment to TQM. These six companies did this for the first time in 1992, each taking about 100 university people in their sessions. In 1993, another six companies participated in this "University Challenge" program. In addition, IBM has awarded one million dollar grants to eight colleges and universities around America to implement TQM in the 
curriculum. In five years, the U.S. will see the results of these model schools' efforts.

With business playing a key role in the initiation of TQM at colleges and universities through companies like Motorola and IBM, there will be a significant increase in the application of TQM to higher education in the next five to ten years. In order to more fully understand CQI (TQM), a discussion of specifically what it entails and the role of statisticians in this important effort follows.

It is important to note that every organization implementing CQI must define it in a way that fits its culture. Instead of "customers", "workers" and "products", university personnel might prefer to simply speak of "students". Students, like customers, are provided a service; like workers, they are asked to produce research papers, homework problem sets, projects, etc.; and like products, they are "sold" to business, industry, government and service agencies after graduation. There are other customers, however, because faculty members could think of themselves as customers of administrators, support staff and students; faculty are also processors of raw materials, like students and research ideas; and suppliers of services to students, parents, administration, businesses, scholars, and legislators or others with political power. Moreover, university faculty also have management responsibilities. Whatever terminology is adopted, $\mathrm{CQI}$ requires looking at the interdependence of roles people play in a system of continuous improvement.

\section{Definition of CQI (TQM)}

The term "Total Quality Management" suggests managing quality in an overall way. What, however, is meant by "quality"? Deming (1986) relates it to "satisfying the needs of the consumer, present and future". Juran (1989) suggests quality is "fitness for use". Roberts' (1993) definition is worth noting as well: "Continually serving customers better and more economically, using the scientific method and team-work, and focusing on removal of all forms of waste". Note the emphasis on continuous quality improvement and in teaching people in an organization to view themselves as part of a larger systematic operation. The main elements of a CQI program in any organization are highlighted in the discussion which follows. Terminology used to describe these elements is taken from the business sector, but examples from education are used to illustrate key concepts.

\section{Managers}

Managers must define an organizational mission and vision. They must recognize the need to change to improve substantially, which often means adopting new paradigms to achieve major improvements. Managers should become coaches and facilitators, build trust, drive out fear, benchmark, take risks, and eliminate waste. Rather than sub-optimize leaders must coordinate the optimization of the total system. Presidents, Vice-Presidents, Deans, and Department Chairs should serve on multilevel teams with faculty and staff members in order to make more effective decisions for colleges and universities. Too frequently major decisions are made without student or faculty input.

\section{Customers}

Managers should listen to internal and external customers, recognize the high cost of losing them, and try to delight them by exceeding their expectations. It is often valuable to use customers as members of quality improvement teams. However, in education, we gather very little useful data about our curricula from students, alumni, and employers. Worthwhile alumni and student surveys are needed to measure customer needs and expectations. 


\section{Employees}

Employees must see how they contribute to an organization's final product or service. This ultimately contributes to a healthier staff morale and a healthier work environment in general. Employees must have proper training and be given necessary tools and resources, after which they can be empowered to make decisions and correct errors within the limits established by the system. Training in team-building and team decision-making is essential. Maintenance staff, support staff, and student services staff should all be able to make decisions that directly affect them without engaging in bureaucratic "red tape" to improve colleges and universities. It should be noted that appropriate training is expensive. If possible, an internal expert in CQI should be found so that training can be done at the right time, on the right topics, and in the right amount. Often much training is a waste if it is not used, or if it is a "quick fix".

\section{Suppliers}

Suppliers should become trusted members of decision-making teams or even partners in business, which makes possible programs like "just-in-time" delivery of goods and services. Secondary schools are definite suppliers of college students; thus they should be included in partnerships. Open lines of communication should be established at the very least between schools in the immediate geographic area and local colleges and universities.

\section{Statistics}

The importance of basing decisions on data and using the scientific method cannot be overemphasized. Often, in the beginning of an organization's CQI implementation plan, simple measures or metrics like number of defects, cycle time, costs, absenteeism, market share and simple statistical summaries can bring great improvements. In higher education too often, the numbers are there (as in survey results) but nothing is ever done with these metrics. Data should lead to action. For example, if attendance in a large lecture class if below 50 percent, serious consideration should be given to changing the format if the course is important to the curriculum. Otherwise, the course should be dropped.

\section{The Role of Statisticians and Statistics}

Our personal experiences suggest statisticians should be well-acquainted with TQM ideas and philosophies and be leaders in their worldwide implementation in higher education. During the 1991 fall semester, RVH took a "quality journey", visiting 20 companies and 8 universities and attending major quality improvement meetings. He tried to determine what produces quality products and services and what statisticians' roles are in those processes. He also wanted to understand how to apply TQM techniques to higher education (Hogg \& Hogg, 1993). MCH took her own "quality journey" for her dissertation research on TQM in higher education, visiting two community colleges and two universities practising TQM. She interviewed faculty, staff, administrators, and students about their perceptions of their respective schools' TQM implementation. Due to these experiences, most of our examples are associated with American institutions.

When RVH asked business and industry leaders "What are the roles that statisticians and statistics play in TQM implementation?", the answers ranged from phrases like "teaching statistical thinking", "getting relevant data in the real world", to "communicating with good statistical summaries". That is, in education, statisticians must learn to "practice what they teach" and assist university personnel at all levels in collecting and interpreting data in order to make better decisions.

It was clear that approximately 85 percent of the improvements in the companies RVH visited 
had been made due to changes in the organizational culture. Only about 15 percent of the improvements could be attributed to statisticians and statistical methods, and those were primarily connected to the use of one or more of the seven basic statistical tools: flowcharts, cause-and-effect diagrams (Ishikawa's fishbone), Pareto charts, histograms, run charts, scatterplots, and control charts. (Ishikawa, 1976) Advanced statistical techniques, which accounted for a small fraction of the 15 percent, included design of experiments, regression and response surfaces, multivariate techniques involving partial least squares and principal components, and time series. RVH estimates that culture and simple tools are doing 99 percent of the quality job in the companies that he visited. After the easier problems get solved, however, there will be a greater need for better technology and advanced statistical methods.

Statisticians who possess good communication skills are well-suited to becoming leaders in the quality movement. Deming and Juran have been the "gurus" thus far; however a number of younger statisticians like Blan Godfrey (of the Juran Institute), Jeff Hooper (of AT\&T), Brian Joiner (of Joiner Associates), Bill Parr (of the University of Tennessee), Larry Sherr (of the University of Kansas), Ron Snee (of Joiner Associates), and Doug Zahn (of Florida State University) are providing innovative leadership in CQI. If educators want to prepare future statisticians for the new work environment, courses that contain the following technical elements should be taken by undergraduate as well as graduate majors:

- the scientific method and the Shewhart/Deming cycle of Plan, Do, Study (Check), Act

- problems associated with measurement

- how to collect relevant data (surveys and experiments)

- an appreciation for statistical thinking

- basic seven statistical tools

- good graphical methods

- an understanding of common and special causes and, in general, variability

- Deming's analytic studies and emphasis on prediction

- computational statistics

- messy and large data sets

- advanced topics such as design, time series, multivariate analysis, regression (including nonlinear), response surfaces, reliability, and basic stochastic processes.

In addition to the technical and theoretical components listed above, statistics students should be well-trained in the following non-technical areas: exposure to the quality culture espoused by Deming, Juran, et al.; the importance of teams; participating in actual team projects; the importance of good communication and interpersonal skills; participation in oral individual and group presentations; working on projects from inception to completion; and the use of case studies as a means to examine important problems.

In a sense, we are suggesting that a certain percentage of statisticians become "quality scientists". These statisticians should study the organizations that will employ college graduates. They should also acquire management and people-oriented skills. University courses in statistics would then better represent expected behaviors in organizations at large to students. That is, "quality science" could very well become an interdisciplinary field.

With this knowledge-base formed, statisticians could take the lead in the academic CQI movement. Statisticians could conduct workshops; consult in business, industry, and government; assist campus offices in their process-mapping (flow-charting) efforts; assist campus offices in conducting institutional effectiveness/customer satisfaction surveys; engage in research and teaching efforts through CQI processes; and in general make themselves available to those who want statistical services. Once statisticians are involved in a CQI effort, research topics related to TQM will abound. There are important problems to solve in higher education, and interested statisticians (quality scientists) 
can help.

\section{Colleges and Universities using CQI}

Some major universities in the United States are starting to use principles of quality improvement in daily operations and customer service to students; among those are Georgia Tech, Maryland, North Dakota, Oregon State, Penn State, Purdue, Rochester Institute of Technology, and Wisconsin. For example, "Penn State University's Integrated Model adopts Deming's systematic view of organizations, in which quality stems from the comprehensive interface between suppliers, design, processes, output, and customers: By improving the competencies of incoming students, by developing curricula more responsive to customer needs, by improving the effectiveness and efficiency of instruction and administrative operations, and by developing an effective feedback loop from customers to process, Penn State University will be institutionalizing the continuous improvement of the entire educational process." (Seymour, 1993, p.27)

Two-year colleges have also done some ground-breaking work in the implementation of CQI processes throughout their organizations. Fox Valley Technical College (FVTC) in Appleton, Wisconsin has been the leader in this effort. FVTC has pursued CQI for more than seven years. Their "Total Quality Leadership Council" is a multi-level team that makes decisions affecting the entire college. Other CQI-related projects at FVTC include: cafeteria improvements, registration process improvements, teaching improvements, and the implementation of quality competencies expected of graduates in all sixty academic programs. The CQI program at FVTC is truly an institutionwide system of organizational change, much of which can be attributed originally to the ideas and paradigm-shifting vision of the former President of FVTC, Dr. Stanley Spanbauer (Spanbauer, 1992).

To read further about specific case studies (including Boston College, the Maricopa Community College system, and the University of Wisconsin-Madison) in CQI efforts, examine the May/June 1993 issue of the journal Change.

On the international quality scene, a suggested reading is the April 1993 issue of Higher Education. Articles deal with accounts of CQI initiatives on the following campuses: the University of Ulster in Northern Ireland; the University of Wolverhampton in Wolverhampton, U.K.; South Bank University in London, U.K.; and at Aston University in Birmingham, U.K. The U.K. has been a leader in the application of business and industry principles to higher education.

Those who want to consider CQI should begin with background reading before starting any implementation effort. The book, Quality: Transforming Postsecondary Education, by Ellen Earle Chaffee and Lawrence A. Sherr (1992) provides a good start for any university that wants to consider such a major transformation in culture. Two books by Mary Walton $(1986,1990)$ also serve as a good starting place. After that, Deming's Out of the Crisis (1986) is an excellent reference. In the health care area, Curing Health Care (by Berwick, Godfrey, and Roessner, a 1990 publication) provides many good case studies in which the elementary statistical tools are used. Joiner Associates' The Team Handbook (1991), with Peter Scholtes as the major contributing author, is particularly useful in team building exercises, and a special edition for education is due out in 1994.

Two titles that are beneficial in terms of learning about changes in leadership, changes in thinking about customers, and general organizational change are: Thriving on Chaos, by Tom Peters; and Re-Engineering the Corporation, by Hammer \& Champy (1993).

\section{Nonacademic Improvements}

Frequently, CQI projects are more successful on the nonacademic student services side of a university's operation than they are on the academic side. Several examples follow. 
- Flowcharting an entire process can call attention to many areas that might need improvement. The College of Business at Rochester Institute of Technology uses a "process mapping" procedure with administrative support staff and gives the staff more control over their work. One example is in the course withdrawal procedure. RIT students had previously been going to three or four different places to withdraw from a course. Through process mapping, staff members discovered this "no value-added" activity, and they now take care of the signatures needed. After the advisor's approval, the College of Business simply forwards the form to the Registrar's office, which saves the students time by eliminating unnecessary running around. Chaffee \& Sherr (1992) give an example listing the many steps needed in obtaining travel reimbursement funds at a university. Deming states that one person should be responsible, and it is not necessary to have several persons at various levels sign forms, because then no one reviews the forms very well. The person who is accountable should do the paperwork and that should be the termination of the process.

- Many schools work hard at recruiting and retraining students, yet this process could often be improved. After a student's acceptance, schools frequently overlook the cost of losing that student to another college or university or through attrition. Many students become "lost in the shuffle" of higher education. For whatever reason, they transfer or drop their registration. Georgia Institute of Technology provides an innovative example of process improvement in this area. In response to high minority attrition rates, particularly in the freshman year, Georgia Tech instituted an academic "pre-season" for incoming freshmen. These students are brought to campus five weeks prior to the beginning of fall semester classes. The topics covered in this time period are designed to help acclimate the minority freshmen to college life. For example, study skills, and what to expect from college are two subjects that are dealt with. Another feature of the program is that each freshman has a minority upper-class member as a mentor. The success rate has been impressive-the 1st quarter retention rate has risen from $88 \%$ to $97 \%$. Georgia Tech is now considering offering the "pre-season" to all freshmen, not just minority students.

- Oregon State University carried out several CQI projects in a pilot program beginning in 1989. Chaffee \& Sherr (1992) report some of the improvements made in areas such as physical plant, budget information, computing services, business affairs, and staff benefits services: "1) Average duration of remodeling jobs reduced by 23 percent; 2) "Budget-status-at-a-glance" form improved to meet customers' needs and cut preparation time by 50 percent; 3) Number of journal vouchers returned to departments to correct errors decreased by 94 percent; 4) Time to process grant/contract documents decreased by 10 percent; 5) Number of phone calls getting initial human response increased by 40 percent" (p. 10).

- At the University of Maryland-College Park, an exemplary CQI program in the Student Health Services Center is worth noting. One team has solved the problem of student "wait time" to see doctors. They determined it would be more effective to set up two.lines, one for students who need to see M.D.' s, and the other for students who need a quick check that a nurse could administer. This has cut wait time down tremendously. Two other teams are in the process of examining the automation of appointment schedules and the improvement of staff morale.

These are just a few examples of the many changes that have been instituted in nonacademic student services areas. For further documentation on this topic, see the May/June 1993 issue of Change.

\section{Academic Improvements}

On the academic side of CQI at colleges and universities, there is more resistance to its implementation for several reasons. One is that faculty individualism and academic freedom are part of the 
nature of being a faculty member. Another is that faculty tend to believe that business should not interfere with education, and some dislike the idea of being "managed" and use of the term "customer" when referring to students. Third, faculty are given inconsistent expectations. Administrators claim that more emphasis will be placed upon improving the status of teaching in the future; yet when it comes to tenure and promotion, most of the weight is still placed upon research and publications.

In fact, current reward systems in higher education at most U.S. colleges and universities imply that additional time spent on teaching is time wasted. If indeed universities truly want to improve teaching, reward systems involving tenure must change. Even the status of tenure as "the ultimate reward" will need to be questioned and examined in light of CQI. Further, if university systems call for improvement in the quality of teaching, the way higher education institutions are rated nationally and internationally must also change. We do not want to imply that research is not important, for it is at major universities. However, a better balance must be achieved in the total reward structure.

Thus, because moving toward CQI on an institution-wide basis is a radical shift in traditional academic procedures, there is much resistance to its implementation. To faculty, there is a certain comfort in the status quo and in keeping academic debates and dialogues alive. Faculty tend to feel threatened when change enters their world.

CQI emphasizes changing the system. To be totally effective, the top leadership must be committed to this movement, because faculty alone cannot institute the changes needed throughout the university. That is, if higher education truly wants a paradigm shift to this new style of management, it will require a comprehensive integration of quality improvements into daily decisions led by presidents and vice-presidents of universities and deans of colleges. As Deming stated, "you cannot expect 'instant pudding'". TQM cannot be installed like carpet, and past efforts have failed because total day-to-day commitment did not exist in these cases. If that commitment does not exist, it may be inadvisable for a particular university to try CQI.

Faculty can, however, lead change in specific processes in Colleges (e.g., of Business, of Engineering, of Education), in departments, in individual teaching methods and in personal quality. A discussion of each of these areas follows.

\subsection{CQI in Colleges: Curricular Improvements}

One step toward meeting the demands of the public is for colleges and universities to examine their curricula, particularly in the areas of business, statistics, and engineering. For example, a few years ago, the College of Business at Rochester Institute of Technology (RIT) was experiencing a higher than average attrition rate at around the junior year. They surveyed students who had either switched majors or transferred institutions to find out why this was happening. Students repeatedly told the College of Business they had experienced feelings of alienation, primarily because they did not take any required business courses until their junior year and thus did not really feel part of that College. This response, echoed by businesses that want to hire graduates with technical and people skills, led to development of a five-quarter sequence of courses required of all freshmen and sophomores in the College of Business, entitled "Business Concepts". During these five quarters, students engage in team building exercises, problem solving processes, and oral presentations, in addition to learning about theoretical aspects of CQI. Current students in the "Business Concepts" sequence are very satisfied.

RIT's College of Business also requires two quarters of cooperative education (internship) credit in every undergraduate business major's program of study. The College of Business has a Placement Office, which assists students in locating suitable internships. Both of these curricular innovations (the Business Concepts course sequence and the internship requirement) deserve praise and recognition for the way that RIT has genuinely met or exceeded customer needs and expectations.

Curriculum and instruction are the areas most likely to be affected by change through CQI 
processes. New degree programs, revamping outdated degree programs, CQI seminars for credit, and faculty development opportunities are four additional suggestions to consider when making departmental and/or college-wide improvements.

In the area of degree programs, an interdisciplinary Masters of Science (M.S.) program in Quality Management and Productivity has proven to be successful at The University of Iowa. The program involves three departments in three different colleges: Statistics in Liberal Arts, Industrial Engineering in Engineering, and Management Sciences in Business Administration. Students take an integrated course program from the three areas, and a critical component is internships for the students between their first and second year of graduate study. While Iowa does not have a Ph.D. in Quality Management, individual ad hoc Ph.D. programs are permitted, and two students are currently enrolled in this academic endeavor. In a way, this is a first effort to train professional statisticians to be "quality scientists".

In addition to exploring new degree programs, consider that certain degree programs may be outdated enough that a major transformation is needed. For example, during the last two years, the University of Tennessee has had a team which radically revised their complete Masters of Business Administration (MBA) program, in order to be thoroughly aligned with philosophies of quality improvement. Statistician Bill Parr played a major role in the revision of the MBA degree.

Another CQI-related project is a seminar involving faculty and students. RVH proposes to, for example, recruit about five professors in the College of Business Administration to form quality teams of about six students each. Then, the quality teams, the professors, and RVH meet together in a weekly seminar on CQI for one semester hour of academic credit for the students. Thus, the quality improvement effort that has recently begun in the Business School at Iowa would be enhanced.

Finally, making it possible for faculty members to continue their own educational experiences is important as well. Formal and informal learning opportunities (seminars, workshops, conferences) across colleges involving faculty and graduate students can assist faculty in working on classroom presentation skills, or for research presentations. It gives colleges a chance to celebrate each other's work and to take advantage of areas of expertise available in-house without bringing in outside experts. This could be done on the departmental level as well.

\subsection{CQI in Departments: Grass-Roots Improvements}

Typically, as projects are implemented throughout a college or university, the primary commitment to CQI comes from top administration. Two excellent examples are found in John Byrne, President of Oregon State University, and Donna Shallala, formerly the Chancellor at the University of Wisconsin, and currently a cabinet member in the Clinton Administration. Once the President/Chancellor/Provost, Vice Presidents, and Deans "buy in" to the movement, offices and departments on campus that are slated to be initiators of CQI are able to begin work. However, it is not always the case that a college or university has a commitment from its top leaders to CQI. In these situations, there must be champions, committed individuals who will foster an enthusiasm for CQI beginning with training sessions, workshops, etc. on campus. After such champions are found, CQI efforts can start on a "grass-roots" level. This involves finding members of the campus community to participate in ongoing discussion and study of CQI implementation. Here are some suggestions.

Work to increase collegiality within departments. For example, at the University of Iowa, several statistics and actuarial science faculty members participate in "brown bag" lunches. These are often used for improvement seminars.

Promote discussion related to CQI. This might include general sharing of ideas and thoughts about topics like:

- How are courses sequenced in the curriculum? Too often, academicians do not worry about this and hence sub-optimize by concentrating on individual courses. 
- A few teachers and students from different sections of the same course could brainstorm about ways to improve the course.

- Different rates and ways in which students learn. Perhaps ask a guest speaker to address issues associated with different learning styles, as not many academicians understand these.

- Strategies to incorporate student feedback. Often, complaints are "blessings from the sky". How do instructors take student comments and actually make changes from them? Which comments should be taken seriously, and which can be dismissed? Colleagues who have made significant changes based on student input could share ideas and strategies for making such changes.

- Explore ways of improving as teachers of statistics by visiting each other's classes. Suggestions could be made by colleagues as to how one could better prepare a class period. Videos of a few class periods can be very instructive. In addition, discussing decisions made prior to class in preparation for class could be helpful.

- Discuss grading philosophies, and how grading should be handled under a CQI system. Grading is a sensitive issue and should be handled with care. Students in any class should understand that all of them can get "A's", and that students are not competing for "A" grades. Too often we encourage only individual efforts; and yet, team efforts are so important once students join the working world. It is vital for professors to model teamwork for their students in and out of class, and to celebrate and/or reward it in grading systems for courses. Modeling teamwork also includes structuring departments as teams with team members who collaboratively and cooperatively make decisions.

- How to use team activities in class, not only using quality team feedback projects, but in promoting group problem-solving and decision-making.

- Discuss "waste" associated with academic activities and how it can be cut down, if not eliminated. The "waste" in academics includes the seemingly endless amounts of paperwork associated with university policies and procedures. In this case, a task force could be constructed to examine the department's administrative processes in order to make a policy or procedure simpler and to maintain higher levels of customer satisfaction.

Academic advising needs improvement on a grass-roots level. Students often get poor advice from their advisors who may allow students to take anything they want, or allow students to take "easy" courses just to get by until graduation. The authors believe part of the reason poor advising occurs is that university personnel tend not to view programs of study as systems with interrelated and interdependent parts. All degree programs, whether they are bachelors, masters, or doctoral levels, should be treated as systems. Academicians should be ashamed of themselves if they offer programs that have no integration of course work, no vision, and no sense of a coherent whole.

Departments should work toward reduction of variation. This is a major CQI principle that can be implemented in departments by, for instance, reducing the variation among instructors who teach beginning courses that are prerequisites for other courses. This means giving students the same course in every section of multi-section courses. Instructors follow a given course outline in terms of material and assignments, yet employ their own individual teaching style. Honoring individual initiatives in these situations is important; however a balance with team effort should be achieved in order to make quality improvement in a department possible.

Begin team projects soon after reading and learning the basics. For a first effort, select a problem with good chance for a successful resolution. Appoint a team that is familiar with the operation and its problem. Select a leader and/or a facilitator who have prior knowledge of CQI. Do not expect results overnight, and do not get discouraged. Celebrate small successes along the way. 


\subsection{Individual Instructors: Course and Methodology Improvements}

In addition to organization-wide CQI efforts (in universities, colleges, or departments), individuals can take a lead role in improving their own instruction.

To demonstrate to students that quality is not an abstract concept, RVH has integrated a student data-collecting activity into a mathematical statistics class of about 30 students. When the students come in during office hours, they must show RVH a time series, plotting the number of hours spent on the course between each class period. RVH tells students that he expects an average of more than two hours, preferably three, so that they know what kind of commitment they must make in taking the course. In addition, RVH asks them to assign a letter grade to the hours they have spent studying for class. These run charts may explain why a student is not understanding course material, particularly if he/she indicates low average time or grades. If the times and marks are high and a student still lacks comprehension, he or she might not have adequate background in mathematics and/or statistics for the course.

Fred Mosteller (1988), a statistician at Harvard University and past President of I.S.I., recommends "one minute drills". These involve taking a sample of students during the last minute of each class period who place comments on a slip of paper noting: 1) The topic they thought was the most important during that class period; 2) The topic they thought was the "muddiest"; that is, what they did not understand about class; and 3) What they wanted to know more about. Mosteller reports that the "muddiest point" draws the most valuable responses. At the beginning of the next class period, these comments are then addressed by the instructor.

Ted Wallenius of Clemson University suggests a modified version of the "minute papers". RVH hands out slips of paper to six students at the end of the period prior to the one in which he asks students to comment. (For instance, the instructor might hand out six slips of paper on a Monday, and these students know that they need to write comments for him/her at the end of Wednesday's class). This method produces two additional benefits: 1) students tend to write more detailed and better questions about course material, and 2) students tend to read ahead, which reduces the "mud" that might be perceived about class material. While this modification results in a biased sample, it truly helps students understand the benefits of advanced preparation. For RVH, the "minute papers" have been exceptional ways of getting immediate feedback on teaching and courses. They have proven to be more effective than end-of-the semester evaluations, as students who are in a given class can benefit from improvements made by the instructor throughout the term in which it is taught. However, for any of these feedback techniques to work well, the instructor must take the attitude that "complaints are blessings", for often they suggest ways to improve.

Another useful way of acquiring student feedback is through the use of student "quality teams". These "teams" should be composed of six to ten students with whom the instructor meets once a week to discuss issues that are relevant to teaching and content unique to that course. Often, extra credit must be awarded to help motivate students to volunteer for an extra meeting per week. Students find it is well worth their time to be part of quality improvement in the classroom, in addition to developing skills that will help them in their future workplaces.

Student-constructed surveys conducted several times per semester are frequently used in "quality team" projects to aid the instructor in making improvements continuously. In a large elementary business statistics course, Ian Hau (1991) employed a team of six students who brainstormed for ideas for course improvement and conducted surveys. Action, based upon survey results, produced the following improvements: problems students had with computer exercises dropped from 78 percent to 22 percent with Hau preparing handouts for student use; problems with blackboard presentation dropped from 58 percent to 8 percent by Hau's use of thicker chalk; and problems associated with the overhead projector went from 82 percent to 46 percent by repositioning the projector on the lecture hall floor. Total impact of the project resulted in continuous improvement, and it provided a starting point for Hau and his students who took the course in subsequent semesters. 
Another example of instructional change prompted by CQI involves electronic response technology employed in Colleges of Engineering and Business courses at the University of Maryland-College Park. Students take courses in what is called the "Teaching Theatre" (there is one in both buildings), and they are able to instantaneously provide computerized responses to instructors at any given point during class. For instance, if a student is not understanding something, he/she can express that to the instructor anonymously and immediately. The anonymity of response is appealing to students; thus, they may be more candid in any given response.

Angelo \& Cross (1993) have published Classroom Assessment Techniques, which is devoted entirely to practical suggestions for assessing course-related and instructor-related student feedback. One excellent example is the "punctuated lecture" for which the purpose is to assess course-related learning and study skills, strategies, and behaviors. "This technique requires students and teachers to go through five steps: listen, stop, reflect, write, and give feedback. Students begin by listening to a lecture or demonstration. Then, after a portion of the presentation has been completed, the teacher stops the action. For a quiet moment, the students reflect on what they were doing during the presentation and how their behavior while listening may have helped or hindered their understanding of that information. They then write down any insights they have gained. Finally, they give feedback to the teacher in the form of short, anonymous notes." (p. 303).

Instructors simply do not have enough data about their students, and perceptions become clouded about student needs. The solution is to "do statistics", that is, collect data. Bear in mind most needed improvements in business, industry, and education are noted by simple statistical summaries. Thus, educators should adhere to a modification of the "KISS" ("Keep It Simple Stupid") principle; "Keep It Simple Statistician!"

\subsection{Personal Quality: Personal and Professional Improvements}

At the most elementary, most basic, and yet most important level, persons who are interested in CQI tend to be people who possess the interest in ability to develop a vision of personal quality. Before discussing CQI at the individual instructor, department, college, and university levels, faculty may want to formulate their own personal quality vision first.

Personal quality can best be defined as making continuous improvements in an individual's personal and professional life. One data-collecting activity which can contribute to a person's quality vision is the "personal quality checklist" (PQC), an idea discussed in Quality is Personal: A Foundation for TQM, by Roberts \& Sergesketter (1993). Their PQC involves keeping daily track of improvement in personal habits and workplace activities. A tally is make on a list of six to eight improvement items each time one "faults". Sergesketter \& Roberts have on their lists: 1) being not one second late for appointments, meetings or classes; 2) answering the phone in two rings or less; 3 ) returning phone calls the same or next day; 4) responding to letters in five business days; 5) having a clean desk; 6) file items properly to avoid searching for something misplaced or lost; 7) performing a small task, rather than putting it in a "hold pile"; and 8) discarding incoming junk promptly. Total "defects" are plotted each week and attempts are made to reduce the number of personal defects.

Personal quality also involves making the relevance for each person involved clear in order for CQI to be successful. An associate dean at an Eastern U.S. university stated that until members of his administrative support staff can make quality personal to their jobs and to them, TQM does not work. The same holds true for faculty, staff and administrators at all levels of any higher education organization. 


\section{Conclusion}

The suggestions submitted in this paper are some that have worked at a few colleges and universities thus far. If an institution, college, department, or individual instructor is just beginning to look at $\mathrm{CQI}$ as a way to operate on a day-to-day basis, the key is to never lose sight of customer satisfaction. Those who initially are successful in team projects can be trainers for others to follow. When the enthusiasm for CQI on campus becomes contagious, it will not stop: it becomes a way of life.

However, individuals in a department, college, or university, cannot sustain a CQI effort over time. Eventually all persons on campus need to at least consider, if not for themselves, for students, the benefits of CQI in higher education. From the personal level to the public level, CQI is on the horizon as the way of the future in academia. It is possible that all of higher education can become "obsessed with quality" with people's personal quality visions at the core of the CQI movement. As Bob Galvin of Motorola stated, "Quality is very personal". RVH and MCH believe that significant and positive efforts in TQM will result in worthwhile satisfaction and rewards.

\section{Acknowledgement}

We thank David Moore for his time and effort in assisting us through the initial drafts of this paper. In addition, we thank the three reviewers who gave us significant amounts of feedback to help us guide our vision.

\section{References}

Angelo, T. \& Cross, K.P. (1993). Classroom Assessment Techniques: A Handbook for College Teachers. San Francisco, CA: Jossey-Bass Publishers.

Berwick, D.M., Godfrey, A.B. \& Roessner, J. (1990). Curing Health Care: New Strategies for Quality Improvement. San Francisco, CA: Jossey-Ball Publishers.

Chaffee, E.E. \& Sherr, L.A. (1992). Quality: Transforming Postsecondary Education. ASHE-ERIC by The George Washington University, Washington, D.C.

Change (May/June 1993). Special Issue on TQM in Higher Education. Change, 25, No. 3, 3-70.

Coate, E.L. (1993). The Introduction of Total Quality Management to Oregon State University. Higher Education, 25, 303-320.

Deming, W.E. (1986). Out of the Crisis. Cambridge, MA. Massachusetts Institute of Technology Center for Advanced Engineering Study.

Hammer, M. \& Champy, J. (1993). Re-Engineering the Corporation: A Manifesto for Business Revolution. New York, NY: Harper Collins Publishers.

Hau, I. (1991). Teaching Quality Improvement by Quality improvement in Teaching. Report No. 59, Center for Quality Productivity Improvement. Madison, WI: University of Wisconsin.

Higher Education (April 1993). Special Issue on TQM in Higher Education. Higher Education, 25, No. 3, 227-375.

Hogg, R.V. \& Hogg, A.L. (1993). A Quality Journey. Total Quality Management, 4, No. 2, $195-214$.

Ishikawa, K. (1976). Guide to Quality Control. Asian Productivity Organization.

Juran, J.M. (1989). Juran on Leadership for Quality: An Executive Handbook. New York, NY: Free Press.

Mosteller, F. (1988). Broadening the Scope of statistics and Statistical Education. The American Statistician, 42, 93-99.

Peters, T. (1987). Thriving on Chaos: Handbook for a Management Revolution, New York, NY: Knopf Random House.

Roberts, H.V. (1993). Using Personal Checklists to Facilitate TQM. Quality Progress, 51-56.

Roberts H.V \& Sergesketter, B.F. (1993). Quality is Personal: A Foundation for Total Quality Management. New York, NY: The Free Press.

Scholtes, P.R. et. al. (1991). The Team Handbook. Madison, WI: Joiner Associates.

Seymour, D. (1993). The IBM-TQM Partnership with Colleges and Universities: A Report. Washington, D.C.: American Association for Higher Education.

Seymour, D. (1992). On Q: Causing Quality in Higher Education. New York, NY: Macmillan.

Spanbauer, S. (1992). A Quality System for Education. Milwaukee, WI: ASQC Press.

Walton, M. (1986). The Deming Management Method. New York, NY: G.P. Putnam's Sons.

Walton, M. (1990). Deming Management at Work. New York, NY: G.P. Putnam's Sons.

Wilson, R. (1991). "Undergraduates at Large Universities Found to be Increasingly Dissatisfied." Chronical of Higher Education, 37, A1+.

Zahn, D.A. (1990). Current Challenges in Statistics: Large-Lecture Courses. Communications in Statistics-Theory and Methods, 19, 4419-4434. 


\section{Résumé}

L'enseignement supérieur entre dans une nouvelle ère en raison de l'évolution de la manière dont sont perçus les collèges et les universités. On exige de plus en plus une meilleure performance, soul l'angle de l'enseignement et de la compétence des diplômés des collèges. Un modèle pour les ètablissements d'enseignement supérieur sont les nombreuses sociétés qui ont réussi à améliorer leur performance globale et leurs produits à l'aide de la "gestion de la qualité totale". Celle-ci est surtout axée sur une satisfaction accrue du consommateur grâce à une structure intégrée permettant l'examen des relations existant entre divers éléments à l'échelle du système ainsi qu'une prise de décisions guidée sur des données en vue de réduire les erreurs et le gaspillage dans les processus. Pour ce faire, les gestionnaires doivent créer un environnement dans lequel les employés sont fiers de leur travail et ont le pouvoir d'apporter des changements.

L'article porte sur la nécessité d'améliorer sans cesse la qualité de l'enseignement supérieur, sur le rôle des professeurs de statistique dans l'évolution de l'enseignement supérieur, sur certaines des stratégies et des techniques utilisées par les collèges et les universités pour la gestion de la qualité totale aux niveaux de l'établissement et des départements, sur les possibilités d'action qui s'offrent à chacun des enseignants pour apporter des améliorations à l'enseignement supérieur, et sur le rôle et l'importance d'une vision personnelle de la qualité dans une tentative globale visant un changement organisationnel. Les auteurs ont de plus voulu que l'article soit une source d'idées pour améliorer l'enseignement et pour alimenter la réflexion sur les questions découlant de la gestion totale de la qualité dans un établissement d' enseignement.

Mots clés: Amélioration continue de la qualité; gestion de la qualité totale; qualité personnelle; changement organisationnel.

[Received August 1993, accepted May 1994] 